\title{
Participação popular e assistência social: contraditória dimensão de um especial direito
}

\section{Beatriz Paiva}

Universidade Federal de Santa Catarina (UFSC)

\section{Mirella Rocha}

Universidade Federal de Santa Catarina (UFSC)

\author{
Dilceane Carraro \\ Universidade Federal de Santa Catarina (UFSC)
}

\section{Participação popular e assistência social: contraditória dimensão de um especial direito}

Resumo: Este artigo responde ao interesse de problematizar concepções teóricas referentes às políticas sociais, versando sobre nova cartografia de categorias referentes ao debate sobre participação popular na política de assistência social. Em rota de ruptura com a desabilitação do caráter protagônico das massas, o estudo é parte do compromisso de pensar a política social para além do tradicional âmbito, como mera estratégia de acomodação de conflitos, privilegiando seu potencial político-emancipatório. Procura ainda contribuir na análise das políticas sociais na atualidade, no que se refere às possibilidades ou interdições, enquanto estratégias de combate à desigualdade e de garantia de direitos, lastreada pela disputa política do excedente expropriado das massas.

Palavras-chave: políticas sociais, participação popular, assistência social.

\section{Popular Participation and Social Assistance: a Contradictory Dimension of a Special Law}

Abstract: This article responds to the interest in analyzing theoretical concepts referring to social policies, and discusses a new cartography of categories related to the debate about popular participation in social assistance policy. Breaking with a trend that seeks to disable an active role by the masses, this study is part of a commitment to expanding thinking about social policy beyond the traditional realm - in which the policy is simply a strategy to accommodate conflicts - and to emphasize its political and liberating potential. It also seeks to contribute to the analysis of current social policies, concerning possibilities or interdictions, as strategies to fight inequality and guarantee rights, based on the political dispute for the surplus expropriated from the masses.

Key words: social policies, popular participation, social assistance. 


\section{Advertências preliminares}

O peculiar percurso da assistência social, na sua afirmação como política pública integrante do tripé da Seguridade Social, foi tímido na admissão dos usuários como participantes da formulação, da gestão e do controle social desta especial área, reproduzindo o histórico legado tutelador e clientelista. A dificuldade de participação direta de seus usuários, principalmente cidadãos das classes subalternas, inscreve-se, ademais, no âmbito da cultura política autoritária e impopular, que traumatizou a história brasileira em passado não tão distante. Também a participação institucionalizada - restrita a determinados institutos da democracia burguesa e ao momento das urnas - é produto do contexto pós-ditadura militar, que não ultrapassou as estratégias de "transição pelo alto", cerceando a construção de uma real democracia no país. Embora a obrigatoriedade do controle social e da participação da população nos destinos das políticas públicas tenham se afirmado como diretrizes constitucionais, em 1988, a plena tradução destes princípios está longe de ser uma realidade na política brasileira.

Este desafio, transposto ao contexto do Sistema Único de Assistência Social (SUAS), em mais de uma década de implantação da Lei Orgânica da Assistência Social (LOAS), é de fato imenso. Nesse sentido, o Conselho Nacional ao apresentar o ciclo de Conferências da Política de Assistência Social do biênio 2008/2009, que tinha como tema central: "participação e controle social", definiu o seguinte objetivo:

Aprofundar, de maneira participativa e crítica, o processo de avaliação da Política Pública de Assistência Social, na sua trajetória de afirmação como direito social, com a participação efetiva dos usuários. [...] visando aprofundar e alcançar uma nova densidade aos processos de participação, que melhor combine as estratégias representativas e as de exercício direto da cidadania popular (CNAS, 2009, p. 4).

A meta ambicionada era atingir um "patamar novo e robusto da construção democrática nesta especial área de realização de direitos", onde as conferências, em cada cidade, estado e no evento nacional, deveriam se converter em fóruns decisivos para o êxito desta importante tarefa. O diagnóstico preliminar do Conselho Nacional de Assistência Social (CNAS) antecipava que

[...] um dos grandes desafios nesse processo é a participação do usuário nos espaços de controle social e na gestão dos serviços socioassistenciais, transitando da inaceitável condição de subalternidade para sua efetiva e autônoma afirmação como sujeito de direitos (CNAS, 2009, p. 4).
Esta empreitada é de grande monta, decerto. A reversão de um legado histórico de subalternização (YAZBEK, 1993) requer um processo amplo e articulado, para além de acontecimentos pontuais e solenes. Nossa hipótese é que os espaços de controle social, através desse modelo representativo e restrito, tendem a reproduzir os mesmos impasses da democracia representativa, isto é, o distanciamento das massas e das suas reais necessidades, a corrupção, a representação de interesses pessoais e privados, a burocratização etc.

É importante considerar também que a dificuldade de inserção em movimentos sociais e em espaços de participação dos sujeitos individuais e coletivos se ampliou muito nos últimos anos, à medida que as transformações econômico-sociais das últimas décadas foram tornando cotidianamente mais difícil a reprodução material da grande maioria da população. A dura realidade da vida, que a torna mais embrutecida e penosa a cada dia, faz com que a ausência de condições materiais para participação dos usuários - que ocupam seu cotidiano na tentativa de garantir a sua reprodução material, social e a de sua família - seja percebida como uma fatalidade. Portanto, os óbices para a participação são também tidos como inevitáveis ou incontornáveis; nada mais cômodo. A indignação com a desigualdade e injustiça é metamorfoseada em resignação.

Se a dificuldade de reproduzir a vida não gera condições automáticas para conscientização e mobilização, capazes de nutrir de convicção e estímulo a expectativa para a participação, aí sim é mais urgente e necessário o trabalho da política de assistência social na perspectiva do protagonismo popular, se pretendemos dotar de possibilidades a luta contra a desigualdade e a favor da garantia de direitos sociais plenos e universais.

Sendo assim, nossa análise procura apontar a imperiosa necessidade de se alterar práticas e projetos conservadores ainda reeditados das mais diversas formas e nos mais distintos âmbitos desta especial política pública, especialmente no Brasil. Realizar o direito à assistência social numa perspectiva efetivamente democrática implica, pois, no reconhecimento concreto do protagonismo popular, cujo exercício pelos usuários sujeitos de direitos, de partida, deve enfrentar o elitismo na sociedade e na política pública também.

A distorção e ocultamento das contradições sociais, ao lado da constante inabilitação e desqualificação da capacidade criadora das massas, são mecanismos ideológicos intensos, que geram cotidianamente o embotamento das consciências, a alienação e a resignação. Por tudo isso segue absolutamente atual e necessária a estratégia reivindicada por Antonio Gramsci, admirável pensador e militante revolucionário italiano, preso e morto no cárcere fascista de 
Mussolini. Para ele, a "reforma intelectual e moral" era uma dimensão decisiva dentro do horizonte de transformação socialista e democrática. Portanto, é uma bela e vigorosa exigência, crítica contundente e arma de combate aos (des)valores típicos da ordem burguesa, como o individualismo, a ganância, o consumismo, a competitividade exacerbada, o ceticismo e a aceitação passiva da desigualdade e da tirania que de forma brutal fabricam a desumanização da vida, como mecanismos subsidiários à exploração de classe. Será que há lugar e tarefa para a política pública de assistência social contra este projeto de dominação e a favor da construção da luta social e radicalmente democrática no Brasil?

Debruçar-se sobre esta questão exige refutar a triste e insistente localização para a assistência social no âmbito do sistema de direitos sociais brasileiro, ou seja:

\begin{abstract}
[...] significa romper definitivamente com seu aprisionamento numa esfera governamental periférica ou residual, reprodutora de estratégias usuais de mistificação das desigualdades e de ocultamento das suas causas, que reduz suas respostas a programas pontuais, pretensamente reformadoras das condutas individuais e grupais, sem qualquer conteúdo ou potência transformadora libertária.

Esta tradicional demarcação lhe imprimiu um mistificado caráter de ação meramente adjutória - como forma compensatória e parcial de alívio da pobreza - e revestiu suas ações e medidas de precários aparatos, em termos de recursos financeiros, humanos e materiais (PAIVA, 2006, p. 7).
\end{abstract}

Nesse sentido, as reflexões desenvolvidas neste ensaio têm o propósito, pois, de problematizar o desafio da participação popular na política de assistência social ${ }^{1}$, atualizando sua relevância no bojo da agenda de luta democrática do país.

\section{Elementos para a agenda da participação popular na política de assistência social}

$\mathrm{O}$ atual estatuto jurídico-político da democracia brasileira no país já experimentou mais de 20 anos de construção histórica, desde a aprovação da Constituição Federal. Lá foram consagradas importantes conquistas, sem que todavia fossem superadas outras tantas contradições, especialmente às referidas ao conteúdo da cidadania em sua dimensão econômica e social. Há, porém, avanços no desenho da Seguridade Social. Entre outros, a criação de Conselhos com reuniões periódicas e a realização de Conferências em períodos regulares têm contribuído com a arquitetura institucional da gestão, incluindo diferentes sujeitos políticos no controle social, com potencialidade para socialização de informações an- tes reservadas ao espaço do Estado, mas com limites crescentes, há que registrar.

Esse intervalo histórico de mais de duas décadas intercalou caminhos e descaminhos, na institucionalização dos direitos sociais a serem afiançados por meio de políticas públicas de Estado, mas se a Constituição Federal é portadora de avanços históricos consideráveis na história brasileira, por outro lado, as grandezas do legado da desigualdade social e dos longos anos de desaquecimento da economia geraram obstáculos importantes, somados ao ainda vigente processo de contrarreforma neoliberal.

As constantes ameaças de desregulamentação hoje com o espantoso espectro da Reforma Tributária - e as frequentes emendas a nossa Carta Suprema seguem como um dos maiores desafios de toda a sociedade ${ }^{2}$.

Desta forma, os inúmeros projetos de emendas constitucionais e a política macro-econômica não passaram ao largo das políticas sociais nestas duas décadas, por esta razão, o frágil estatuto jurídico-político da cidadania no Estado brasileiro, submetido à dinâmica de permanente mutação e da dependência, tem impedido a consolidação de possantes responsabilidades sociais, no sentido da viabilização de direito condizentes às exigências de justiça social, equidade e universalidade. O cenário paradoxal dessas duas décadas é analisado por Couto (2006, p. 153), em uma ilustrativa passagem:

\begin{abstract}
No atendimento às demandas da população na perspectiva universalista da Constituição de 1988, muitas foram as disputas para que esses princípios de universalidade fossem alterados, sempre invocando a insuficiência de recursos para aplicá-los e a necessidade da focalização de atendimento nas populações mais pobres, visando a racionalização dessa aplicação. Em tese, não se discutiu o princípio, mas os principais atos desses governos dirigiram-se para o seu descumprimento.
\end{abstract}

A investida das oligarquias e de seus representantes no Congresso pela desconstitucionalização de direitos e pela privatização das riquezas naturais e empresas estatais ao longo dos anos 1990 foram marcadores contundentes das limitações da democracia formal, recém conquistada após as primeiras eleições presidenciais diretas. No mesmo diapasão, é um forte indicador de que as classes populares no Brasil sofreram e ainda sofrem um penoso processo de imobilização e silenciamento, cuja reversão está a inquietar sujeitos políticos alinhados com as causas populares em nosso país.

Mesmo com as medidas e iniciativas sociais levadas a cabo nos dois mandatos do governo Lula, parece oportuno observar os inúmeros acontecimentos que perpetuam o modelo econômico conservador, com o 
evidente continuísmo do projeto neoliberal implantado desde os anos 1980 em toda a América Latina.

A regra é o cumprimento dos compromissos que garantem a crescente acumulação pelo setor parasitário-financeiro do grande capital, o que tem exigido com graus diferenciados decerto - o acionamento de medidas claramente impopulares, a saber: a) ampliação do superávit primário; b) manutenção das altas taxas de juros; c) intensificação das medidas de ajuste fiscal; d) contrarreforma da previdência para o funcionalismo público; e) demarcação legal para as parcerias público-privado, em atividades econômicas estratégicas para o país; f) reforma universitária errática e parcial; g) tentativa de privatização do SUS, pela proposta de transformação das unidades de saúde em organizações sociais; h) continuidade da proposta de proteção social de caráter focalista e meritocrático, com a restrição ao princípio da universalização firmada em 1988; i) incentivo ao agronegócio, com a protelação das medidas para reforma agrária; j) insensibilidade à degradação ambiental e ao desmatamento da Amazônia; k) entre outros.

De outro lado, já em 2003, o governo Lula põe em marcha a recomposição das medidas de transferência de renda, unificando-as em torno do Programa Bolsa Família, sob a Lei n. 10.836 de 2004, com regulamentação no Decreto n. 5209/2004 (BRASIL, 2004). Todavia, no "passado que não quer passar", as iniciativas encaminhadas pelo atual governo tangenciam o desafio da vigorosa articulação política e social capaz de enfrentar a ideologia conservadora que naturaliza a pobreza e condena à impotência as iniciativas de investimento público no campo dos direitos sociais.

Sabemos que o Programa Bolsa Família é a principal proposta de "combate a pobreza" no país. É um programa que atua em todo território brasileiro e atinge um público de mais de cinquenta milhões de pessoas, trabalhando, porém, unicamente com famílias em situação de pobreza (com renda mensal por pessoa de $\mathrm{R} \$ 70,01$ a $\mathrm{R} \$ 140$ ) e extrema pobreza (com renda mensal por pessoa de até $\mathrm{R} \$ 70)$. Os critérios de inclusão no programa são referentes a renda mensal da família, que não pode passar de R \$ 120 por pessoa, devidamente cadastrada no Cadastro Único para Programas Sociais. Os valores pagos pelo Programa variam de $\mathrm{R} \$ 22$ a $\mathrm{R} \$ 200$ de acordo com a renda mensal por pessoa e o número de crianças e adolescentes de até 17 anos de idade. Além disso, o PBF opera na dimensão das condicionalidades ${ }^{3}$, ou seja, para fazer parte do Programa é necessário manter as crianças e adolescentes em idade escolar frequentando a escola e cumprir os cuidados básicos com a saúde, ou seja, o calendário de vacinação e a agenda pré e pós-natal para gestantes e mães em amamentação.

Ainda sob a baliza do Programa Fome Zero, algumas análises apontam como controvérsias seu ca- ráter extremamente focalizado, o que indicaria a priorização de critérios conservadores e mitigatórios de condução deste Programa. Martins (2007), a partir de estudos realizados pelo Instituto de Pesquisa Econômica Aplicada (IPEA), infere, além disso, que os resultados do Programa, em um primeiro momento, não corresponderam às metas desejadas. Vítima de equívocos de proposição, o Fome Zero pretendeu um desenho conhecido e fracassado: sugeria uma estratégia quase mágica de articulação entre governos e sociedade, numa tentativa de reedição da mítica "participacionista", sem forte arranjo técnico-político transformador. Desse modo, como Programa o Fome Zero saiu logo de cena, dando lugar a outro carro-chefe: o Programa Bolsa Família.

A marca "Fome Zero" segue presente nos sítios do Governo Federal e nas campanhas, programas e projetos, principalmente aqueles desenvolvidos no âmbito dos Ministérios da área social, pois "Fome Zero" passou a ser uma meta estratégica, cuja principal medida é a associação combinada entre uma proposta embrionária de segurança alimentar e nutricional e a transferência de renda, por meio do Programa Bolsa Família.

Marques e Mendes (2005) expõem que programas condicionados de transferência de renda, a exemplo do Bolsa Família, são o cerne dos projetos de enfrentamento à pobreza recomendados pelo Banco Mundial e pelo Fundo Monetário Internacional, de modo que a implementação de tais programas não se confrontam com o sistema de dominação neoliberal, submetidos aos artífices majoritários dos interesses de setores vinculados ao capital internacional. Avaliam ainda que a natureza liberal e meramente integrativa das políticas sociais desta natureza pode se configurar como instrumento poderoso de manipulação política junto aos segmentos da população hoje atendidos pelos novos programas, sobretudo o Bolsa Família. Tal destino adverso só será superado caso os programas, reconfigurados, sejam incorporados às provisões públicas permanentes que consignam direitos sociais universais, como a educação integral para crianças e jovens, e as garantias em termos do acesso à terra para os produtores rurais pobres e ao trabalho urbano formal, que interrompam a trajetória da precarização e superexploração próprias de nosso país e continente.

Pois bem, é fato que programas como o Bolsa Família constituem as estratégias mais recomendadas pelos organismos multilaterais no que se refere à implementação de políticas de transferência de renda aos setores mais empobrecidos da população; é fato também que o governo Lula alcançou índices históricos de aprovação, principalmente durante o último ano. Entretanto, importa assinalar que a principal contradição não emerge especificamente do Programa Bolsa Família, mas do ocultamento dos vín- 
culos de classe da política social em geral, quando submetida às inflexões neofuncionalistas e conservadoras. Ao passo que se camufla, e assim se interdita, a complexa e tensa disputa pelo excedente real historicamente expropriado das massas trabalhadoras, permanece o império da despolitização, que contribui fortemente para a reprodução da subalternidade e da alienação. A hipótese aqui reivindicada é que a politização dos conflitos democráticos decorrentes da disputa pelo excedente econômico pelas classes sociais, a serem traduzidos em políticas públicas justas e universais, pode vislumbrar um horizonte para redução das desigualdades sociais, que também são históricas e produto da mesma expropriação.

A suposição de que o amortecimento do conflito social no Brasil decorre do êxito da área social do governo Lula precisa ser melhor investigada, agora com a massificação das medidas de transferência de renda no país. No entanto, para além de análises simplistas que condenam a ampliação de programas como o Bolsa Família, em virtude da sua possível influência nos resultados eleitorais, é preciso atentar para o que realmente importa: a ausência de um desenho político radicalmente democrático e universal a estruturar as medidas de proteção social no Brasil.

Cabe referenciar que, em termos de alocação orçamentária, não é desprezível a destinação de recursos paras as ações de transferência de renda socioassistenciais como o Bolsa Família. Pela primeira vez, famílias miseráveis encontram alguma medida de proteção social que seja não contributiva. Mas ressalta-se que os limites são muitos: os valores das prestações são muito pequenos, os recursos concorrem com as políticas sociais já desfinanciadas, como saúde e educação, o orçamento não rompe com a lógica regressiva, os critérios de acesso são altamente rigorosos e excludentes, a gestão terceirizada aos municípios é equívoca, e a sua implementação não se faz acompanhada ainda de um forte aparato técnico, dedicado a fomentar a emancipação política, educacional e cultural para os pais, as crianças e os jovens.

Há um registro importante a fazer: sem um desenho político-participativo radicalmente democrático e popular, as ações, serviços e benefícios da política de assistência social, e do Programa Bolsa Família, permanecerão sob o império da despolitização, operada pela perda de vínculo de classe destas políticas públicas com as disputas históricas aos recursos públicos e à riqueza socialmente produzida. No que se oculta tais vínculos, impede-se o combate da destinação dos recursos públicos ao velho sistema de privilégios, para enfim redirecioná-los na perspectiva do combate às desigualdades sociais. Não há luta social ou movimento político popular que paute a mobilização coletiva contra esta institucionalidade. Quase tudo permanece como nos modelos tradicionais, uma ação política governamental ambígua, que oscila entre o apelo humanitário e uma versão ainda estigmatizadora da pobreza ${ }^{4}$.

Mencionamos quase tudo porque não devemos ignorar que a ampliação de espaço em torno da implantação do Sistema Único da Assistência Social (SUAS), portador de um projeto - ainda que limitado - de enraizamento do Estado no provimento das medidas socioassistenciais -, abriu a inédita possibilidade de organização e prestação da política de assistência social de maneira efetivamente pública, em superação ao predomínio quase exclusivo do atendimento pelas entidades filantrópicas privadas.

Mesmo tendo sido afiançada como direito social a partir da Constituição Federal de 1988 e regulamentada a partir da LOAS em 1993, a política pública de assistência social foi confinada a uma moldura clientelista, ao campo da benesse, da caridade das entidades, a uma esfera residual reprodutora da subalternidade dos usuários. Contudo, como fruto do esforço dos diferentes segmentos que se comprometem com esta política, legitimados pelas deliberações da IV Conferência Nacional de Assistência Social de 2003, materializam-se de forma inédita os princípios da LOAS, através da PNAS/2004 que instala o SUAS. Com o sistema único havia que se inaugurar finalmente um tempo novo para a política de assistência social no Brasil.

\section{A questão da participação no SUAS}

O reordenamento do campo socioassistencial proposto pelo SUAS, traduzindo e superando os termos da LOAS, poderia se constituir em passo importante no trânsito da assistência social ao campo dos direitos. A prerrogativa para este percurso idealizava um desenho renovado, no qual a consolidação dos direitos dar-se-ia mediante a reestruturação orgânica da política pública de assistência social no país.

O novo desenho, no entanto, supõe a matricialidade sociofamiliar como eixo estruturador da política de assistência social, a ser operacionalizada em rede de proteção, com a articulação de serviços, programas, projetos e benefícios, a universalização de acessos, o território como base de organização, a hierarquização de serviços por níveis de complexidade e porte de município, com repactuação de responsabilidades entre os entes federados (BRASIL, 2004).

Com esse genérico desenho, cabe ao SUAS superar a pulverização dos serviços nas entidades privadas e mistas, afirmando o território como base para prestação dos serviços, desenvolvimento de ações e projetos, desta vez públicos e estatais por meio dos Centros de Referência. A proposta incorpora ainda a possibilidade de transferência de poder de decisão, de competências e de recursos, e com autonomia para gerenciamento dos espaços na 
elaboração de diagnósticos sociais, diretrizes, metodologias, formulação, implementação, execução, monitoramento, avaliação e sistema de informação das ações "[...] com garantias de canais de participação local, pois, esse processo ganha consistência quando a população assume papel ativo na reestruturação" (BRASIL, 2004, p. 44). Esta passagem traz uma nuance que deve ser ponderada. $\mathrm{O}$ processo de participação popular, ou "local" na linguagem hesitante, não resulta em mudanças rápidas - consistentes - nem o aludido "papel ativo" também pode ser exigido ou almejado como pré-condição para a ampliação dos "canais de participação", como se coubesse troca ou recompensa. Por mais que esta sentença não represente uma lógica utilitarista, ela é suficientemente mal formulada para permitir esta interpretação. Se não há proposta concreta, e se as hipotéticas são condicionadas, é quase evidente que na disputa política que deu origem ao consenso possível da PNAS os atores que negociaram e formataram a PNAS em sua versão final não pretenderam priorizar a participação popular.

O novo papel da política, esperava-se, era de empreender um enfrentamento com o legado de precarização e focalização dos serviços socioassistenciais, forjados pelos modelos privatistas que antecederam ao SUAS. Entretanto, relativo à democratização desse processo, apesar da incerta "garantia de canais de participação local”, não há disposição clara e contundente acerca das estratégias de participação popular, para além do controle social da forma como está colocado na Constituição Federal de 1988.

Tal controle social tem sido portador da utopia de superação da herança autoritária no campo da pobreza e da desigualdade, porém, os limites são evidentes e crescentes. A história dos governos autoritários e burocratas, que conduzem de forma centralizada a gestão das políticas públicas, demonstra que tal padrão não é incompatível com o controle social restrito a um tipo de democracia especificamente representativa e liberal, que não democratize para a população o poder de diretamente decidir e participar na gestão e na formulação das políticas públicas.

Ao se tratar especificamente da política de assistência social, esse padrão se agudiza ainda mais. Enquanto a própria política de assistência social historicamente permanece também em localização subalterna no conjunto da gestão pública - até pela sua baixa coalizão política, decorrente da sua impotência na ação e invisibilidade na luta social - o processo de controle social desta área tende a enfrentar ainda mais dificuldades, nas mais distintas expressões. Nessa área, o descaso e a negligência das escalas governamentais acentuam esta herança histórica, ou seja, uma visão que a deixa subalterna em relação às demais, permitindo ser provida por setores sociais corporativistas e conservadores.
O controle social havido na assistência social notoriamente obstaculizou o protagonismo dos usuários sujeito de direitos, amplificando a presença de atores que se mobilizam mais pela ajuda e a caridade, lógico, na disputa por recursos públicos. Tais setores se detêm com mais afinidade às tradicionais políticas, atuando como linhas de transmissão do conservadorismo e reproduzindo, em escala local, o clientelismo e a subalternização dos sujeitos de direito.

Vale ressaltar, portanto, que para além desse controle social, é desconhecido, nos termos da PNAS/ 2004, qualquer arranjo institucional que se dedique a organização/mobilização popular como escopo próprio do processo de fortalecimento do protagonismo popular, finalidade precípua desta política pública.

Nesse sentido, a formulação da PNAS-SUAS não se nutre da concepção de "autonomia crítica", conforme a essencial formulação de Pereira (2007). Ao discorrer sobre a urgência de uma política social que priorize a satisfação das necessidades humanas básicas, em detrimento da referência aos mínimos sociais $^{5}$, a autora fundamenta, em uma dimensão distinta, pois ao mesmo tempo coletiva e individual, o lugar de uma assistência social democrática. Para ela, a "participação" e a "libertação" constituem princípios-chave que orientam a teoria das necessidades humanas, a substanciarem o caminho da autonomia crítica, em uma equação que não pode ser desmembrada, isto é, “[...] participação com vista à libertação humana de quaisquer formas de opressão, incluindo a pobreza" (PEREIRA, 2007, p. 69).

A finalidade da política de assistência social, iluminada por essa perspectiva, toma a participação popular como referência central, com o estabelecimento de um central lugar político para os usuários, o que implica que os sujeitos individuais e coletivos tenham à sua disposição meios objetivos para exercerem papéis sociais significantes na sua vida social e na comunidade. Essa é, pois, uma dimensão necessária da autonomia:

[...] no horizonte dessa noção de autonomia está, em última instância, a defesa da democracia como o recurso capaz de livrar os indivíduos não só da opressão sobre as suas liberdades (de escolha e de ação), mas também da miséria e do desamparo (PEREIRA, 2007,p. 70).

É nesse sentido que o reordenamento orgânico da política de assistência social no Brasil, através da proposta do SUAS, ao reafirmar a atenção as necessidades humanas e introduzir o território como base organizativa, deve ser capaz de atentar para a especificidade de cada território, tanto em consideração às necessidades e às demandas dos usuários dessa especial política pública, quanto e principalmente em consideração às demandas sociopolíticas, do 
conjunto de necessidades e sentidos, que movem as lutas populares em determinado contexto sócio-histórico. Esse deve ser terreno concreto do campo socioassistencial (ROCHA, 2009).

A especificidade da política de assistência social pode ser referenciada no âmbito das respostas concretas à grande massa de trabalhadores informais, desempregados e subempregados, àqueles que não são contemplados com as demais políticas sociais e que seguem à margem da proteção social tradicional, alicerçada na contributividade do trabalho formal. Em um projeto distinto, o direito socioassistencial também deve se destinar àqueles que exigem atenção especial e que lutam pelo reconhecimento da magnitude da vida humana e social em suas diferentes manifestações. Contudo, a especificidade da contribuição política socioassistencial, como integrante da proteção universal da seguridade social, deve basear-se em seu potencial político-estratégico, se e somente se, for referenciada no complexo âmbito da socialização da riqueza coletivamente construída e das estruturas de poder político.

Temos, através dessa especial estratégia, uma fecunda possibilidade de reestruturação orgânica da política de assistência social no Brasil, mas sem promessas e esperanças distendidas. É preciso reconhecer que, além das adversidades econômicas e conjunturais, o direito socioassistencial no Brasil encontra um óbice à conformação do seu caráter público, social e político, que impede a materialidade de uma política universalizadora e não contributiva: a natureza mesma de sua formatação sócio-histórica no país, o modo como sempre foi feito o processamento das demandas dirigidas a assistência social, em geral centralizadas em requerimentos privados, individualizados e com foco prioritário de ação sob o indivíduo vulnerável ou na sua família "em risco" ("aquela que falha", no linguajar do senso comum conservador) e não a necessidade social, histórica e coletiva e muito menos no âmbito da luta de classes.

Ademais, se por si só não é pujante o impacto do novo desenho da Política Nacional de Assistência Social por meio do SUAS, frente à urgência de ampliação e à imperiosa redefinição ideológica do campo socioassistencial, é grave o ainda pequeno investimento financeiro destinado as políticas sociais em geral. Não se interrompeu a tendência neoliberal de desconstrução da ideia-força do direito social, pela via da combinação perversa entre privatização versus contenção relativa do gasto social em relação ao Produto Interno Bruto.

Uma das dimensões fundamentais da agenda de luta dos sujeitos de direitos no âmbito da realização da política de assistência social é exatamente enfrentar esta disputa. Portanto, a participação protagônica dos sujeitos de direitos deve ser fomentada e priorizada em sua essência, pelas medidas políticas públicas e governamentais, no apoio ao processo de luta histórica das classes subalternas pelo acesso ao excedente, a ser potencializado pelas estratégias organizativas populares e pelas medidas de fortalecimento subjetivo e político e de pertencimento ao projeto coletivo da classe trabalhadora, como um governo radicalmente democrático deve pautar.

Desenhar um capítulo efetivamente novo na história da assistência social no Brasil, ou seja, um direito socioassistencial de caráter universal e provisão social não contributiva, cujo motor seja a radicalização democrática e as necessidades humanas das massas, traduz um importante desafio na sociedade brasileira contemporânea: em um cenário político-econômico pouco alentador, enraizar o vínculo políticoideológico do direito socioassistencial com a dimensão da luta de classe.

É passada a hora de articular um amplo e consistente sistema de atenção e proteção no âmbito das necessidades humanas, que abarque a contribuição decisiva das ações socioassistenciais e político-culturais, com estratégias de fomento ao poder popular, imersos em inédita estrutura de financiamento público, desta vez efetivamente redistributivo e democratizante. A reconstrução orgânica da política de assistência social a partir da participação popular constitui-se portanto como uma força expressiva na ruptura do legado histórico que ainda persiste no âmbito dessa política pública.

\section{Considerações finais}

Cabe ressaltar que um processo de expansão da participação política (antagônico ao sistema das elites políticas tradicionais) ordena, portanto, a expressão genuinamente popular, cuja dinâmica - em essência contraditória - não poderá escapar de algum experimentalismo. Mas, como se trata de alcançar relevância e substância, almeja-se que tal processo seja política e socialmente transformador. Nesse sentido, a ação dos sujeitos sociais, originários ou incorporados ao movimento de intensificação da participação popular radicalmente democrática, deve instituir nova processualidade, a ser observada e absorvida pela política de assistência social:

Construir 'caminhando a caminhada' revolucionária exige que não se lateralize os desafios decorrentes da complexa tarefa de construção do conhecimento crítico, a serviço das causas da democracia, da igualdade e justiça social. É tempo, pois, de realizar as investigações e desencadear os processos coletivos comunitários voltados para a produção do pensamento popular, uma vez que [...] o 'povopobreza' sempre tem sido manejado, subestimando em sua criatividade e aportes, em sua condição de 
agente histórico. Superar tal alheamento, tanto na teoria quanto na prática política, é um desafio permanente do processo revolucionário. Portanto, decifrar a realidade, burilar ferramentas, fazer parte da construção do conhecimento popular e difundir o saber crítico e comprometido são propósitos essenciais ao enfrentamento e à consequente ruptura com a lógica da dominação e superexploração capitalista, própria da realidade latino-americana (PAIVA, 2005, p. 116, grifos da autora).

Reescrever a história da assistência social no Brasil, haja vista libertá-la do ranço conservador e do papel hesitante que cumpre, desde sua instituição como política pública, requer a construção de um horizonte realmente novo para o direito socioassistencial no país. Nesse sentido, a alternativa que apresentamos, para que o SUAS efetivamente opere a necessária e urgente reestruturação da política de assistência social, refere-se ao reposicionamento do eixo que a estrutura para a centralidade da participação popular.

Dotar as medidas de proteção social de conteúdos e estratégias que deflagrem a efetiva autonomia dos sujeitos é princípio fundamental para avançar na contramarcha dos processos de subalternização política, de exploração econômica e de dominação sociocultural. O fomento à participação popular como instrumento de politização e de desenvolvimento social é parte da recente experiência latino-americana em países de maior dinamicidade política popular, onde a prerrogativa de participação direta - para além das insuficientes estratégias representativas - protagoniza as reformas políticas, sociais e econômicas na perspectiva de construção da ampliação da democracia, em tradução dos valores como a justiça, o protagonismo popular, a equidade e a responsabilidade pública governamental a orientarem a atuação do Estado e classes trabalhadoras.

Por fim, para iluminarmos as referências éticas da difícil agenda de construção da participação popular na política de assistência social, é valiosa a advertência de Sánchez Vázquez (2002), quando ele se dedica ao balanço da "filosofia da práxis", frente à exigência de elevar a consciência da necessidade, da possibilidade e do desejo pela mudança social, a inspirarem os atos práticos necessários a isso:

E é válido na medida em que se mantém a validez de seus aspectos fundamentais: não pode ser negada a necessidade de crítica do presente, do capitalismo (e, portanto, a validez de seu aspecto crítico). Não pode ser negada tampouco a necessidade de um projeto e emancipação ou de afirmação dos valores - de dignidade, igualdade, liberdade - que o capitalismo nega. Não pode ser negado, em terceiro lugar, que a realização do projeto, a transformação do presente rumo à futura sociedade, exige um conhecimento de suas possibilidades, caminhos e meios de realização (VÁZQUEZ, 2002, p. 211).

Face ao exposto, é importante recordar que vivemos na América Latina uma trajetória densa de novos horizontes, em termos da ultrapassagem do legado da precarização das políticas sociais, não obstante as dessemelhanças e a falta de sincronia nos processos políticos que as impulsionam. Tais traços foram marcantes nas formulações neoliberais e contrarreformistas das últimas décadas do século 20 , onde era quase exclusiva a preocupação com a contenção do gasto social, geradora de uma grave omissão estatal, especialmente quando as políticas sociais eram destinadas às maiorias mais necessitadas.

Ao invés de distendida, em razão proporcional à pobreza e às amplas necessidades coletivas, a proteção social era confinada ao gueto da focalização extremada, produtora, portanto, de medidas débeis e impotentes. Portanto, é hora de reivindicarmos a experiência de organização do protagonismo popular, na perspectiva de socialização das estruturas de poder político, capazes de afetar, em favor das maiorias, as decisões vitais no espaço dos direitos sociais, para muito além do que se tem pleiteado como uma participação social exclusivamente representativa e delegativa.

\section{Referências}

BRASIL. Decreto n. 5.209 de 17 de setembro de 2004. Regulamenta a Lei n. 10.836, de 9 de janeiro de 2004, que cria o Programa Bolsa Família, e dá outras providências. Disponível em: <http://www.planalto.gov.br/ccivil_03/_Ato2004-2006/ 2004/Decreto/D5209.htm>. Acesso em: fev. 2010.

Ministério do Desenvolvimento Social e Combate à Fome. Secretaria Nacional de Assistência Social. Política Nacional de Assistência Social PNAS; Norma Operacional Básica NOB/SUAS. Brasília, nov. 2004. 
CNAS-Conselho Nacional de Assistência Social/MDS. Orientações para as Conferências de Assistência Social dos Estados e do Distrito Federal. Disponível em: <http:/ /www.mds.gov.br/cnas/vii-conferencia-nacional 2009/> Acesso em: out. 2009.

COMPARATO, F. K. Réquiem para uma constituição. In: LESBAUPIN, I. (Org.). O desmonte da nação. Rio de Janeiro: Vozes, 1999, p. 15-23.

COUTO, B. R. O direito social e a assistência social na sociedade brasileira: uma equação possível? São Paulo: Cortez, 2006.

MARQUES, R. M.; MENDES, Á. Desvendando o social no governo Lula: a construção de uma nova base de apoio. In: PAULA, J. A. de (Org.). Adeus ao desenvolvimento: a opção do governo Lula. Belo Horizonte: Autêntica, 2005, p.143-170.

MARTINS, C. E. O Brasil e a dimensão econômico-social do governo Lula: resultados e perspectivas. In: Revista Katálysis, Florianópolis: Editora da UFSC, v.10, n.1, p. 3543, jun./dez. 2007.

PAIVA, B. A. de . O poder popular na Venezuela e a práxis bolivariana. In: OURIQUES, N. (Org.). Raízes no libertador, Florianópolis: Insular, v. 1, p. 109-128, 2005.

. O SUAS e os direitos socioassistenciais: a universalização da seguridade social em debate. In: Serviço Social \& Sociedade. São Paulo: Cortez, ano XXVII, n. 87, p. 5-24, set./dez. 2006.

PEREIRA, P. A. P. Necessidades humanas: subsídios à crítica dos mínimos sociais. São Paulo: Cortez, 2007.

ROCHA, M. Participação popular nas políticas socioassistencias na América Latina: estudo comparativo entre Brasil e Venezuela. 250 p. Dissertação (Mestrado em Serviço Social) - Programa de Pós-Graduação em Serviço Social, Universidade Federal de Santa Catarina, Florianópolis, 2009.

VÁZQUEZ, A. S. Filosofia e circunstâncias. Rio de Janeiro: Civilização Brasileira, 2002.

YAZBEK, M. C. Classes subalternas e assistência social. São Paulo: Cortez, 1993.

\section{Notas}

1 Este ensaio se vale dos estudos produzidos pela pesquisa Família e participação popular: antinomias dos modelos de proteção social na América Latina, desenvolvida no âmbito do Observatório Latino-Americano - OLA/UFSC, do Instituto de Estudos Latino-Americanos da Universidade Federal de Santa Catarina. O projeto foi financiado pelo CNPq.

2 Neste sentido, Comparato (1999) observava: “As constituições republicanas duraram pouco neste país. Amais longeva foi a primeira que vigorou por 39 anos. Até o final do regime militar, nenhuma delas morreu placidamente; todas foram aniquiladas por atos de força. A atual malferida por 25 emendas em dez anos de existência, passa a sobreviver sob explícita ameaça de morte"(COMPARATO, 1999,p. 15). Esta sentença segue atual até hoje.

3 De acordo com o Ministério do Desenvolvimento Social e Combate à Fome (MDS), as condicionalidades são compromissos que devem ser assumidos pelas famílias beneficiadas nas áreas da Saúde, Educação e Assistência Social. Nessa medida, as condicionalidades possuem o objetivo de responsabilizar de forma conjunta os beneficiários e o poder público.

4 "Nessa medida, reconhecer os desafios técnicos e políticos interpostos à ultrapassagem dos mecanismos de desmobilização e de subalternização, que descredenciam as estratégias de fortalecimento político da população, exige daqueles que se propõem a contribuir na implantação do direito à assistência social pelo SUAS, insistir na participação popular como eixo da política pública, o que requer a ruptura com a lógica desabilitadora do caráter protagônico das massas, na direção de um projeto democrático-radical, conforme o consubstanciado no compromisso ético-político da profissão de Serviço Social.” Essa posição foi desenvolvida em artigo anterior(PAIVA, 2006, p. 8).

5 De acordo com estudos realizados por Pereira (2007) a perspectiva do "mínimo" pressupõe a focalização e a seletividade ao extremo através da supressão ou corte de recursos, escassez no desenvolvimento de ações, projetos e serviços socioassistenciais, restrição ao acesso etc. Por outro lado, a perspectiva do "básico", orienta para outras preocupações, quais sejam, maiores investimentos, mais qualidade na prestação dos serviços, visando “[...] preparar o terreno a partir do qual maiores atendimentos podem ser prestados e otimizados" (PEREIRA, 2007, p. 26). A análise da autora permite perceber ainda que a assimetria desses conceitos tem permitido uma leitura ambígua do direito socioassistencial. Abandonada a tal sorte, aos parcos recursos investidos e à tendência totalitária da esfera sociopolítica brasileira, coube à política de assistência social o compromisso com o provimento de um mínimo obscuro, não balizado, indefinido.

\section{Beatriz Paiva}

beapaiva@gmail.com

Doutora em Serviço Social pela PUC/SP

Professora do Departamento de Serviço Social da Universidade Federal de Santa Catarina (UFSC) 
Pesquisadora do Instituto de Estudos Latino-Americanos (IELA/UFSC)

\section{Mirella Rocha}

mirellafr@gmail.com

Mestre em Serviço Social pelo Programa de PósGraduação em Serviço Social da UFSC Pesquisadora do Instituto de Estudos Latino-Americanos (IELA/ UFSC)

\section{Dilceane Carraro}

dilceanec@gmail.com

Mestre em Serviço Social pelo Programa de PósGraduação em Serviço Social da UFSC

Pesquisadora do Instituto de Estudos Latino-Americanos (IELA/UFSC)

UFSC - Departamento de Serviço Social Campus Universitário Reitor João David Ferreira Lima

Bairro Trindade

Florianópolis - Santa Catarina

CEP: 88040-970 